\title{
Implant-Supported Prosthetic Therapy of an Edentulous Patient: Clinical and Technical Aspects
}

\author{
Luca Ortensi ${ }^{1, *}$, Marco Ortensi ${ }^{2}$, Andrea Minghelli ${ }^{3}$ and Francesco Grande $4(\mathbb{D}$ \\ 1 Department of Prosthodontics, University of Catania, 95124 Catania, Italy \\ 2 CDT Private Practice, 40126 Bologna, Italy; centro.odontotecnico@tiscali.it \\ 3 School of Dentistry, University of Bologna, 40126 Bologna, Italy; andrea.minghelli2@studio.unibo.it \\ 4 Oral and Maxillofacial Surgery, University of Bologna, 40126 Bologna, Italy; francesco.grande6@unibo.it \\ * Correspondence: luca.ortensi@unict.it
}

Received: 20 May 2020; Accepted: 23 June 2020; Published: 1 July 2020

\begin{abstract}
The purpose of this article is to show how to implement an implant-supported prosthetic overdenture using a digital workflow. Esthetic previewing using a specific software, guided-surgery, construction of the prosthesis, and the esthetic finalization are described in this article. Patients suffering from severe loss of bone and soft tissue volume could benefit from the construction of an overdenture prosthesis as a feasible therapeutic choice for functional and esthetic issues of the patient.
\end{abstract}

Keywords: prosthesis; Digital Smile System; overdenture; digital prosthetic planning; atrophic patient

\section{Introduction}

A pleasant appearance is ever more aspired to in the daily life of everyone, at any age. When adverse changes occur to a visible part of the body, the social and psychological impact can be negative for the individual [1]. Among the least well-tolerated changes is edentulism; which, in addition to causing significant functional deficits (chewing, phonetics), involves visible changes of facial esthetics, because with the loss of teeth and the resulting reabsorption of the alveolar crests, there is naturally less support for the soft tissues of the face, which takes on an unpleasant look, regardless of the person's age. Although the total removable prosthetic is doable in a short timeframe and is economical and efficient, it is not easy to make to enhance the function and esthetics of the totally edentulous patient. These two aspects are certainly an advantage, but that is not enough to consider removable prosthesis for the ideal prosthetic therapy. In fact, not even this type of state-of-the-art prosthetic can completely restore chewing capacity and strength in some types of patients [2]. In elderly patients with atrophic maxilla, the implant-supported removable prosthesis (overdenture) is considered a feasible option in the prosthetic treatment plan [3]. When a severe loss of supporting bone structure has already happened, it would be necessary to optimize the soft tissues aspect of the lower third of the face, facilitating, at the same time, home oral hygiene procedures and patient comfort $[4,5]$. Stabilization of the removable prosthesis with a reduced number of implants may present multiple advantages. The biological and economic costs could be contained, the time for oral rehabilitation is shorter, and the long-term success rates are over $90 \%$. In the mandible, two implants seem to be sufficient to obtain good stabilization of the removable prosthesis and the literature does not show statistically significant differences in terms of survival rate and comfort for the patient between insertion of two or four implants, solidified by a bar or with connections not constraining the implants (i.e., ball-attachment or other individual attachment type) [6]. On the other hand, for the upper maxilla the insertion of only two implants is not considered an ideal option if long cantilevers are expected; more predictable results could be achieved with the insertion of at least four implants connected by a metal or titanium 
bar, considering also the shape of the maxillary arch [7]. In this specific therapy, the prosthesis could have a limited palate, improving the patient's comfort and flavor perception [8].

However, the treatment plan of atrophic patients is a challenging procedure for the clinician and also the technician. Several factors should be considered during the treatment planning in order to realize an appropriate oral rehabilitation.

Recently modern prosthetics makes use of digital technologies to support both the diagnostic and the therapeutic phases of patient rehabilitation, facilitating also the communication between the clinician and the lab [9-11].

Traditional removable prosthetics and those supported by implants have benefitted from these innovations both in virtual planning of clinical cases and as a support during the construction phase [12-15].

The purpose of this article is to illustrate, through detailed step-by-step description of a complex clinical case, the construction of an inferior overdenture with implant support, applying the new digital technologies to every phase of the diagnostic and prosthetic therapy, reducing implementation time and analogical phases.

\section{Materials and Methods}

A 70-year old patient came to the dental office complaining of diminished masticatory capacity and loss of retention of both removable dentures. She wanted to improve her smile and facial esthetics, stating she was dissatisfied with the color and poor visibility of her teeth, no matter how big she smiled. The patient also asked to avoid multiple-steps therapies and desired to have a new prosthetic solution in the shortest time as possible. The patient's smile seemed non-harmonious due to dental wear and the inclination of the occlusal planes, which affected her general appearance (Figure 1). The patient gave her written consent to publish photos of her clinical case, including photos of her face.

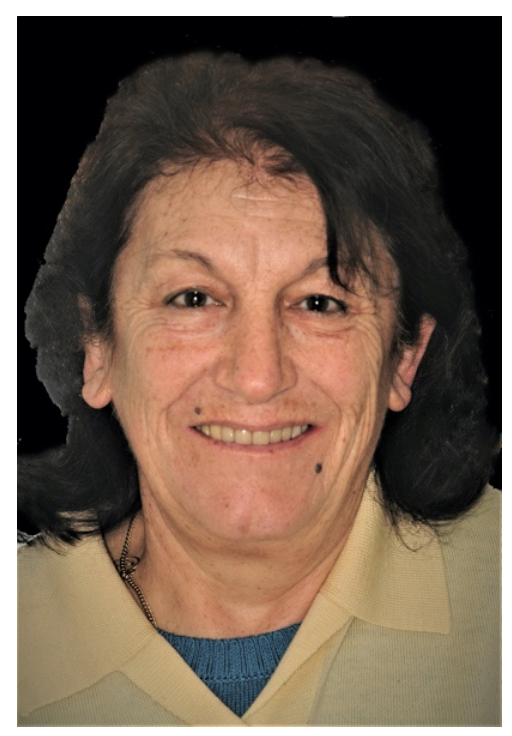

Figure 1. Initial state of the face: a reduction of the vertical dimension is observed with an increase in perilabial wrinkles.

Her history did not show any pathology incompatible with dental treatment and demonstrated that she was in good general health and classified as ASA1. The facial examination showed a reduction of the vertical dimension, with a widening of the nasolabial folds, and diminished tone of the perioral soft tissue, with a generalized deterioration of all facial esthetic parameters (Figure 2). During the intraoral clinical examination, incongruous prosthesis in both arches have been observed (Figure 3). 


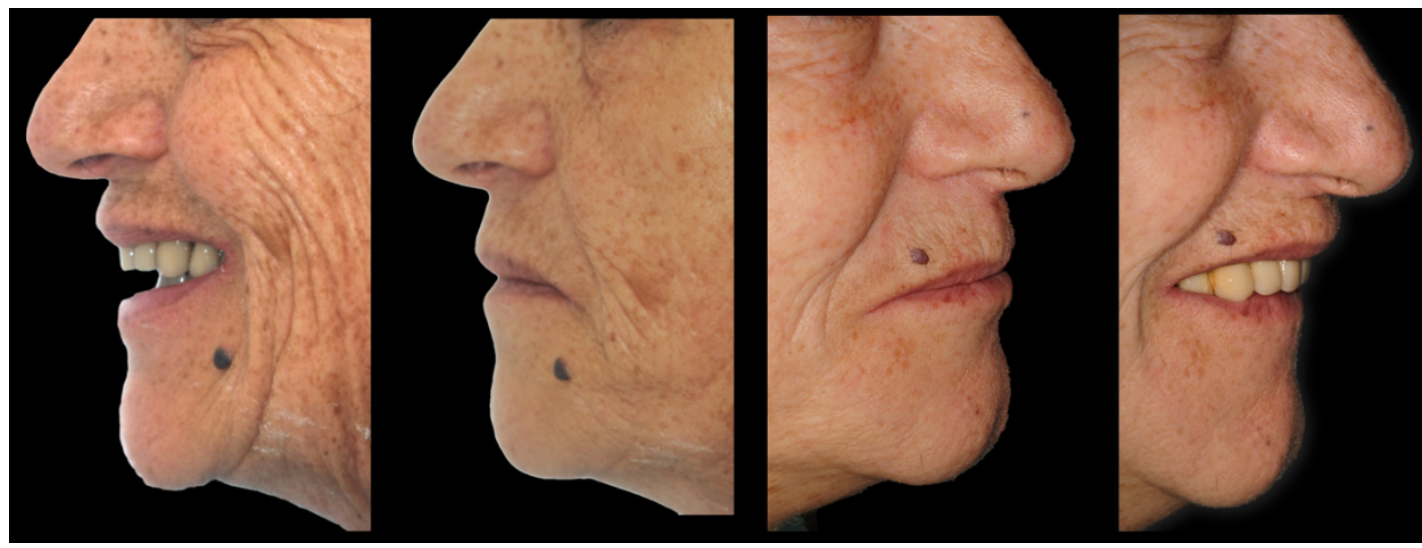

Figure 2. Extraoral facial photos: lateral view.

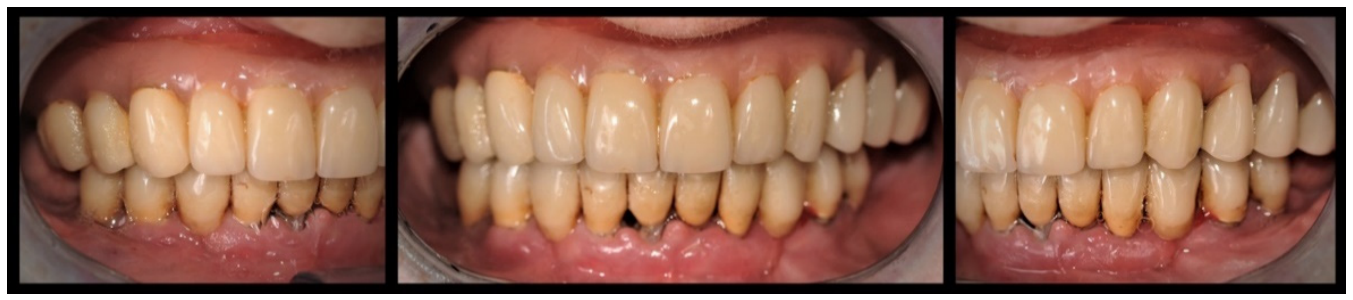

Figure 3. Intraoral photos of the removable dentures.

The upper arch had a full-removable denture, while the lower jaw had a fixed prosthesis supported by few periodontally compromised teeth as shown by the periapical mandibular radiographs, which also show several periodontal pockets, different carious lesions, and bone resorption around the natural abutments (Figure 4).

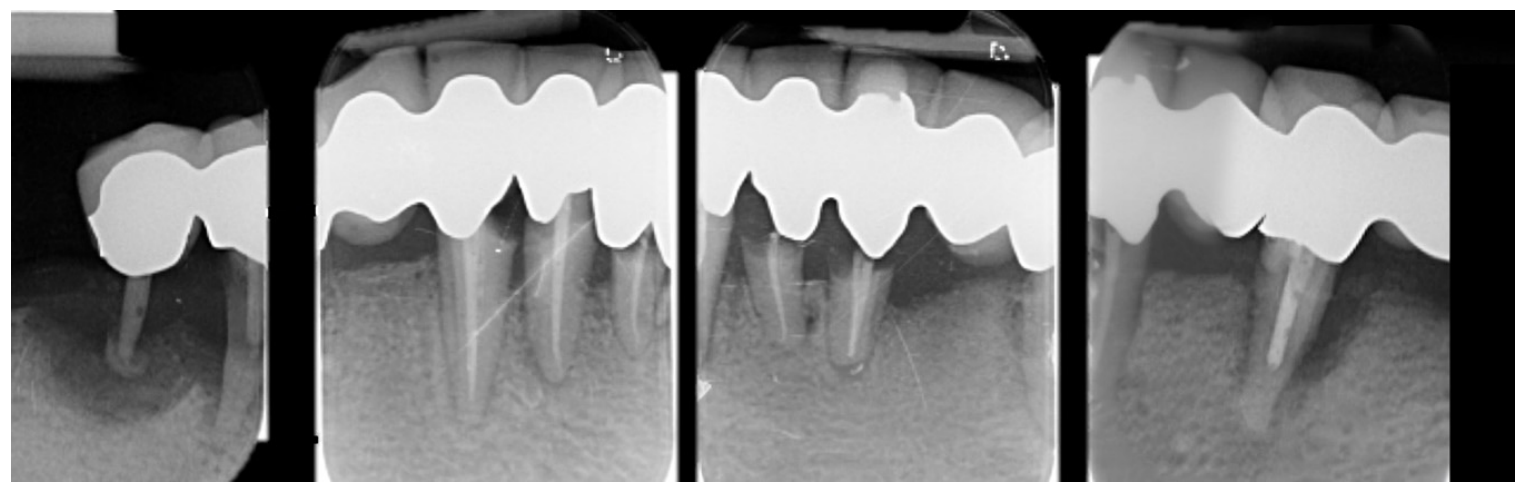

Figure 4. Endoral periapical radiographs of mandibular teeth.

During the first visit, several instrumental analyses were done, such as lateral cephalometric and electromyography. Lateral cephalometry is a valuable diagnostic tool that the authors consider pivotal for formulating a proper treatment plan in a complex prosthetic rehabilitation of an atrophic patient [16]. This x-ray examination enables the study of the hard and soft tissues of the patient's face; in particular, the relationship between the maxilla as well as the spatial position of the upper central incisor and the philtrum. It is also possible to identify the musculoskeletal classification with an appropriate and simple cephalometric analysis [17]. The study of the patient's latero-lateral radiography highlighted meso-facial musculoskeletal typology with reduced occlusal risk. Surface electromyography, using electrodes placed on the masticatory muscles, will allow the clinician to evaluate masticatory activity and to understand whether the occlusal load is adequate or excessive [18]. A measurement of chewing loads produced by the patient is not a secondary element; on the contrary it represents an important 
aspect of comparison for the whole working group, and in particular with the dental technician who will have to take into consideration the extent of these values during the design and construction of the prosthesis.

In the first appointment two photos were taken of the patient's face according to a coded technique for the DSS (Digital Smile System, Bologna, Italy) software [19]. It is important to take photos of the face keeping the patient in a position that is stable and repeatable over time, trying not to change the enlargement ratio between shots. For this purpose, the patient is asked to sit comfortably keeping her back straight while the operator used a camera set on a tripod to stabilize its position in relation to the patient being photographed. The subject had to be positioned so that their Frankfurt Plane (the line that joins the Porion and the Orbital Point) was parallel to the horizon. Once the spatial position of the head is identified, it must remain unchanged with respect to the camera-tripod complex. The patient may wear dedicated glasses used to calibrate the digital pre-rendering software (DSS; Figure 5).

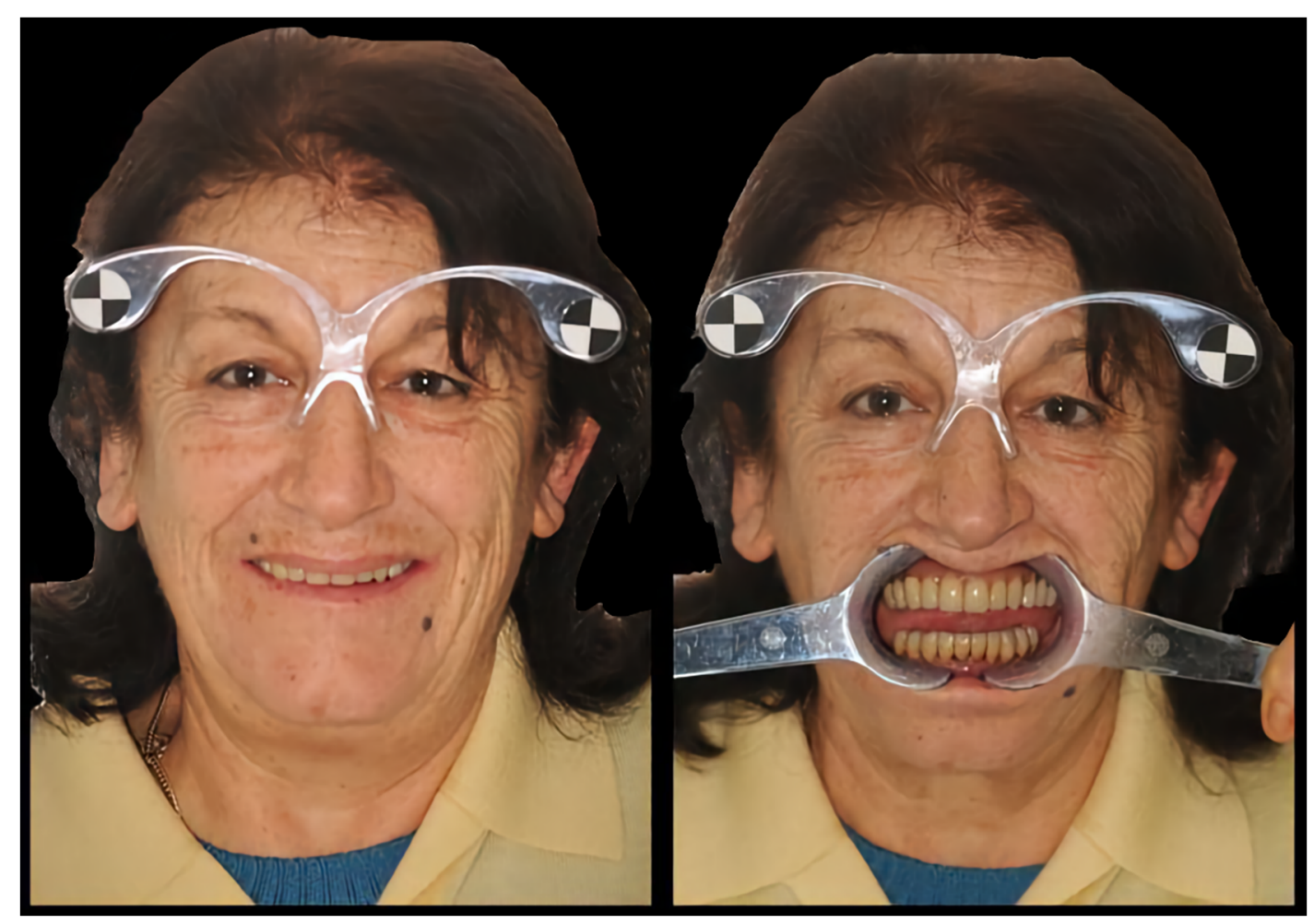

Figure 5. The first facial photo was taken asking the patient to smile and show as many teeth as possible and the second facial photograph was taken with cheek retractors.

The glasses represent a true measuring system that differentiates this software from other similar systems. Thanks to their shape and the presence of calibration markers used as a reference, the glasses facilitate maintenance of the perpendicular position of the patient and the camera. The first facial photo was taken asking the patient to smile and show as much teeth as possible. The second facial photograph was taken with cheek retractors to better highlight the teeth of the patient.

The photographic status is completed with the profile shots of her face and with the intraoral photographs that allow us to make further diagnostic assessments regarding the overall esthetics of her face and its physiognomic characteristics on which we can proceed with our prosthetic therapy [20]. After this phase, the two extraoral photos taken during the first visit were inserted in a dedicated 2D software (Digital Smile System, Bologna, Italy) useful for the final esthetic of the patient.

The Digital Smile System approach using digital techniques for the esthetic preview was only considered a tool for communication with the patient and for the entire dental team. DSS not only allowed the patient to see the esthetic future appearance, but it also enabled production of a prototype 
for the functional check of the digital project carried out [21]. The fact that the patient can see the possible future esthetic results through digital rendering, including the possibility of changes if desired, reduces overall clinical practice time. The procedure requires that the photographs taken be imported into the DSS and then an esthetic preview of the future prosthetic therapy is developed (Figure 6), which consists of a virtual arrangement of commercial teeth present in the software database. The database consists of upper and lower teeth of various shapes and sizes. Anterior and posterior teeth are positioned using the occlusal rim, previously suitably adapted in the oral cavity as a guide. Teeth are chosen according to esthetic and functional parameters and can be replaced with others of different shape or color, if necessary. This allows us to show the patient the possible final esthetic so that she can participate in the therapeutic project in collaboration with the whole clinical-technical team.

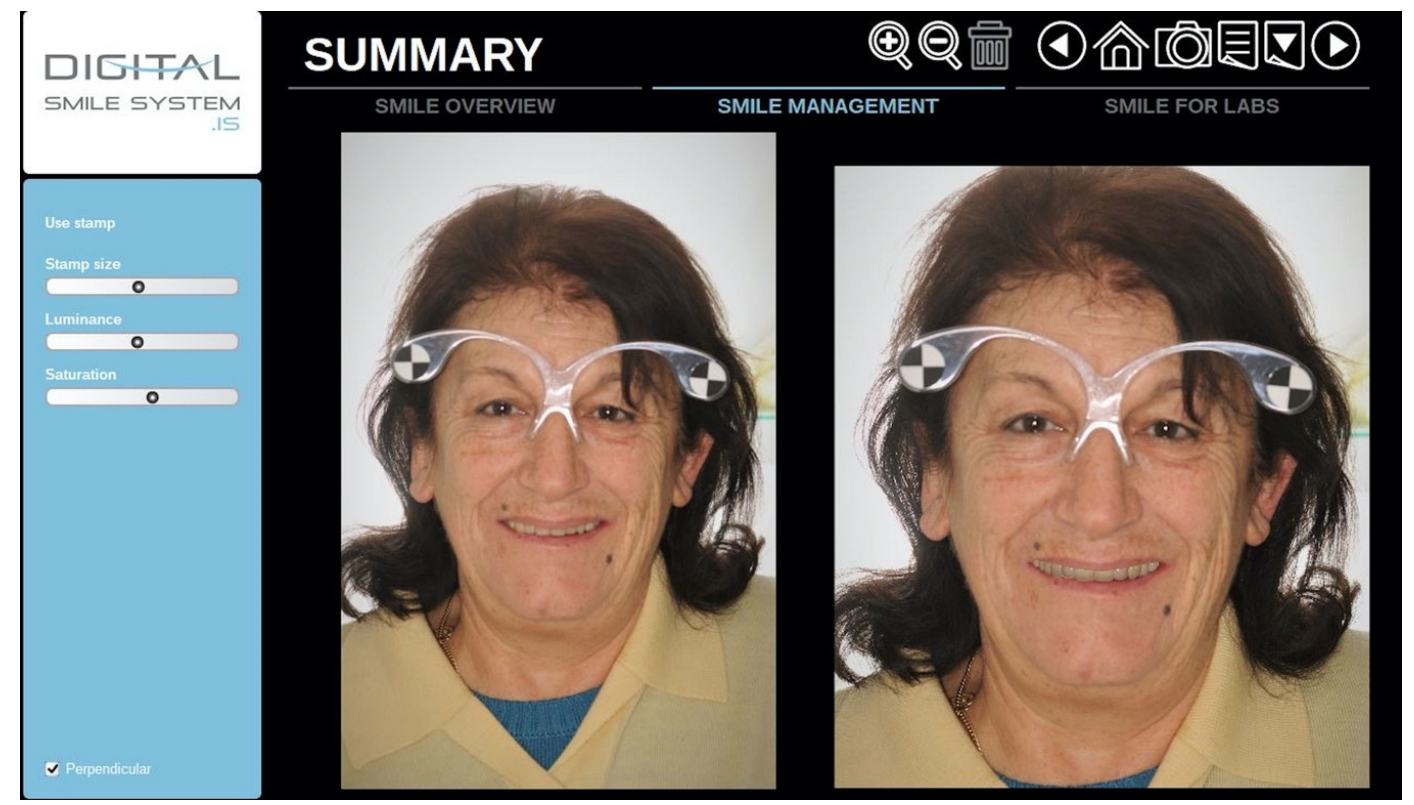

Figure 6. Digital preview of the final esthetic in the DSS software (2D).

In a dedicated appointment, all the compromised dental elements in the lower arch were extracted except the lateral incisor which serves as a provisional anchor of the new provisional lower denture (Figure 7).

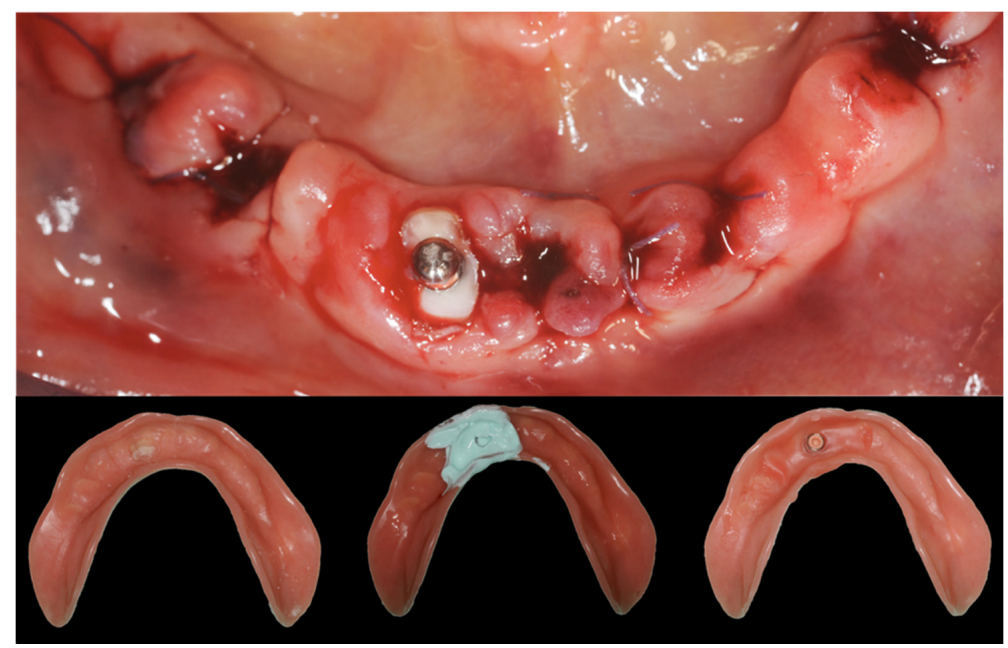

Figure 7. Use of lateral incisor as a provisional anchor for the provisional denture. 
After tissue healing, preliminary impressions of the soft tissue and edentulous arches were made. The authors did not use an intraoral scanner (IOS) because there is no consensus in the literature regarding real efficacy in edentulous subjects [22]. We usually use a high-precision alginate with long setting time useful for tissue functionalization applied in two stages, where possible (only in edentulous subjects): a first impression is made with the alginate mixed with a high consistency (Neocolloid, Zhermack, Badia Polesine, Ro, Italy), it is then dried and modified by removing the undercut parts with a sharp tool and relined with the same material but in a more fluid form to read all the details of the anatomical tissues. The model obtained is scanned with a laboratory scanner (Sinergia Scan, Nobil Metal, Asti, Italy) and a resin occlusion base is built on it by sending a dedicated file to the 3D printer (Asiga MaxUV, Australia), coating it with wax for registration of the centric relationship, esthetic, functional determinants, and vertical dimension [23].

It is important in the upper occlusal rim, during functionalization in the oral cavity, to mark some landmarks; the midline, the canine line, and the smile line. These reference lines will serve in the alignment phase of the occlusal rims in the 3D software (Exocad software, Exocad GmbH, Darmstadt, Germany).

\section{Transfer of Data from the Dental Office to the Laboratory}

Once the virtual teeth arrangement was obtained — and approved by the patient — the file containing the patient's information, the photographic alignments, the libraries chosen, and the work process was transferred to the dental technician laboratory where the file was imported into a 3D software program (Exocad ${ }^{\circledR}$ software, Exocad GmbH). The information file exported from DSS consisted of a PDF format and individual photographs of the patient's face with a customized two-dimensional (2D) virtual smile design.

The files from DSS were then superimposed onto scanned images of the denture. The dental technician used the outline of the virtual smile obtained to place a tooth from the library or to create customized teeth with tools from Freeform (Exocad ${ }^{\circledR}$ software, Exocad $\mathrm{GmbH}$ ) to convert the virtual 2D teeth arrangement into a 3D teeth arrangement [24].

Simply put, "coupling" of the data, thinking that the final image of the mounting, obtained in the $2 \mathrm{D}$ version, represents a face of the volumetric solid corresponding to what is in the 3D version (Figure 8).

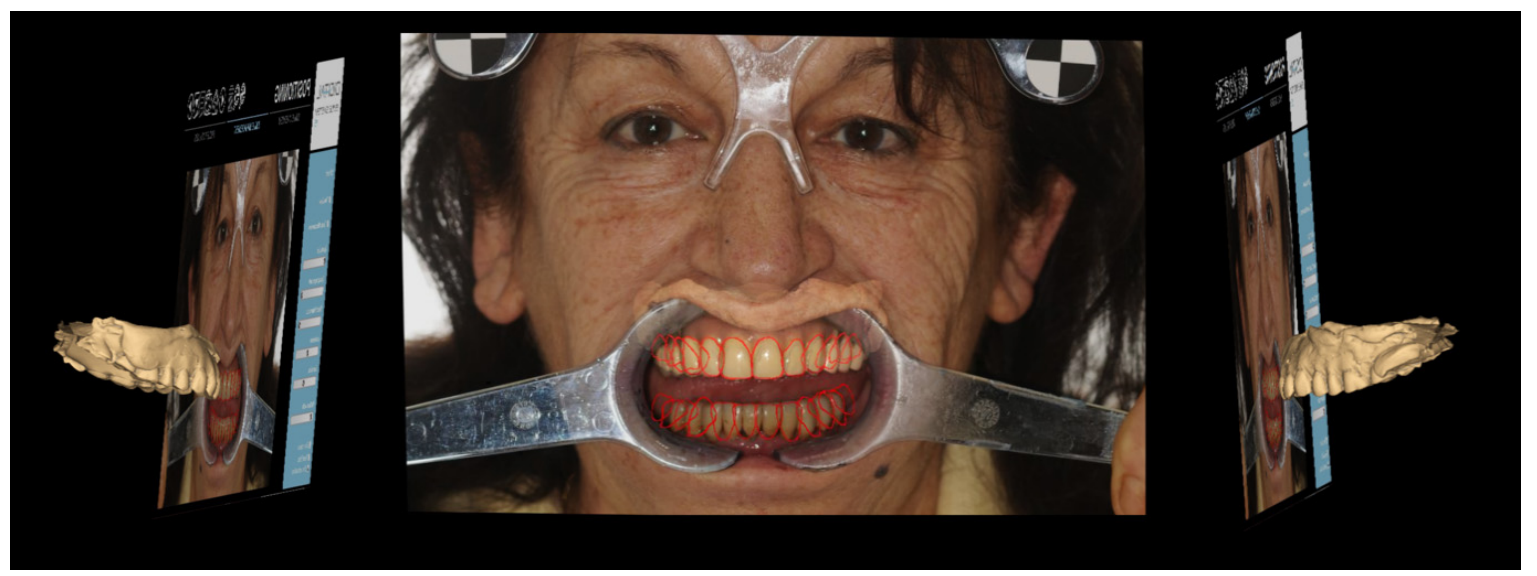

Figure 8. Overlap of the 2D image of the patient's face with the 3D digital model inside a 3D software. The $2 \mathrm{D}$ teeth represent the anterior face of the $3 \mathrm{D}$ solid.

The teeth used from the 3D database represent the volume of the solid, and the 2D teeth are the anterior face of this solid. The dental technician completes the 3D phase, improving the occlusal ratio between the arches (according to the literature) and producing the prosthetic base that will sustain the dental elements. After this phase, CAD (Computer-Aided Design) work can produce a prototype 
that corresponds entirely to the project made with DSS and processed in a 3D environment. The file obtained is sent to a 3D printer (Asiga MaxUV, Australia) and transformed into a prototype to be tested in the oral cavity, verifying the intraoral adaptation, the cranio-mandibular ratio, the esthetics of the smile and face. These prototypes represent the final volume of the final prosthesis. The clinician can make changes without impacting the protocol, in the prototypes, thus modified, can be scanned again by the technician, and overlapped digitally to the original project.

Subsequently the prototype is used as a radiological stent with which the CBCT(cone beam computed tomography) is done, using a dedicated device (Evobite with 3D marker, 3Diemme, Italy), which was adapted to the item with radiotransparent silicon (Elite Glass, Zhermack, Badia Polesine, Ro, Italy; Figure 9).

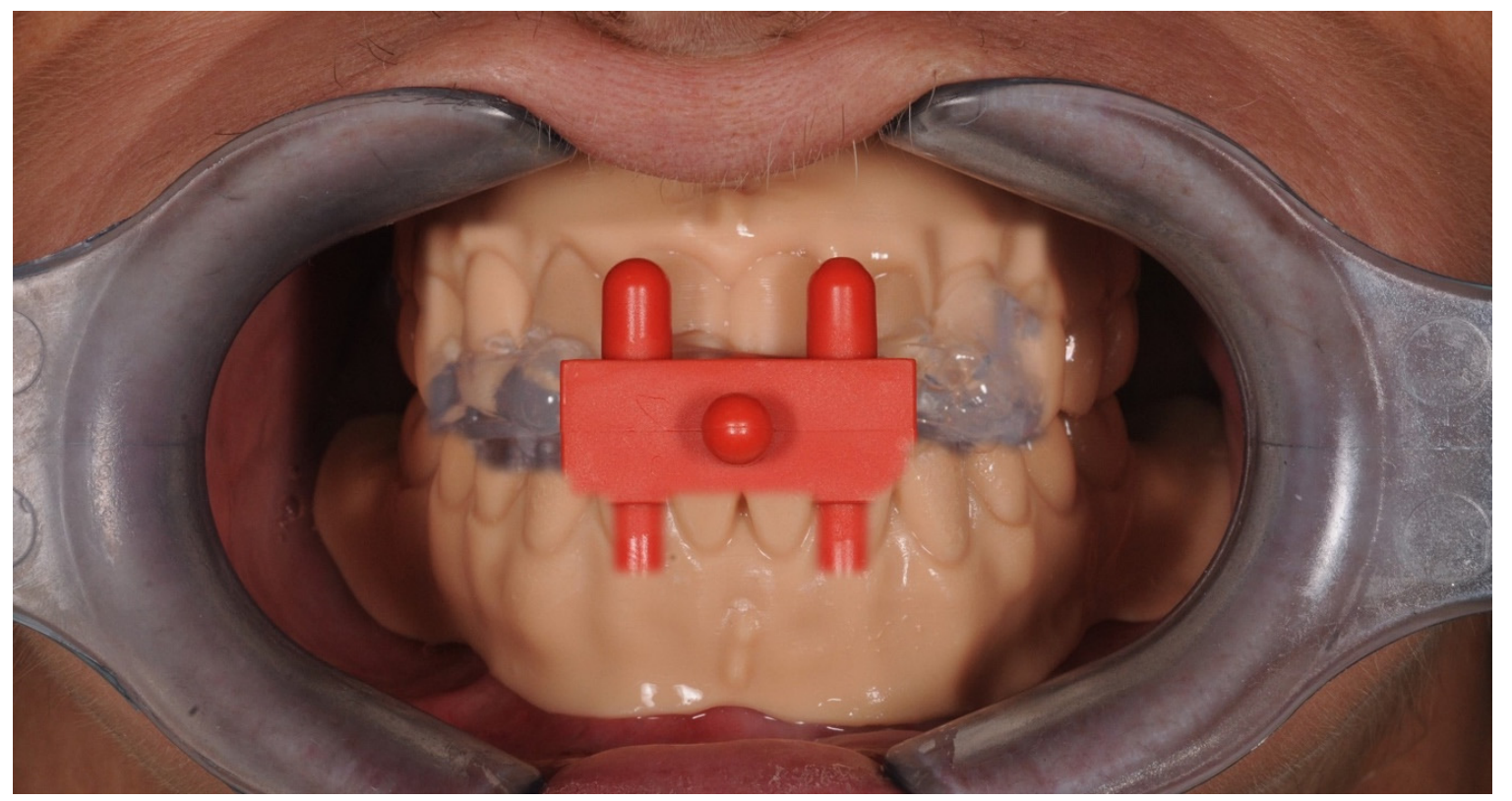

Figure 9. The prototype used as a radiological stent during the conduct of the CBCT (cone beam computed tomography).

The Dicom data resulting from the X-ray and the STL (Standard Triangulation Language) files relative to the anatomical and prosthetic parts obtained from the intraoral scan are imported in a specific implant planning software (Realguide 5.0, 3Diemme, Italy) where, thanks to a dedicated algorithm, they are overlapped using a replicable and controlled procedure. Through use of the implant line database (Thommen Medical AG, Grenchen, Switzerland), the number and position of the implant screws to be inserted via guided surgery are planned. After careful functional and esthetic evaluation and final verification, the prosthetic-driven plan was approved, and a stereolithographic surgical template was made using a newer rapid prototyping technology (New Ancorvis, Bargellino, Italy). Subsequently two prosthetic-driven implants with a diameter of $4.0 \mathrm{~mm}$ and a length of $9.5 \mathrm{~mm}$ (SPI ${ }^{\circledR}$ CONTACT RC INICELL ${ }^{\circledR}$, Thommen Medical AG) were placed, with a dedicated burr kit (Thommen Medical Guided Surgery Kit), in the lower jaw, taking into account the bone quality and quantity, soft-tissue thickness, anatomical landmarks, and the type, volume, and shape of the final restoration. The lateral incisor that acts as provisional anchor for the lower denture, in this phase was maintained in the mouth of the patient for the time necessary for implant loading. Healing screws are positioned directly post-surgically, and the prosthesis is readapted with resilient material (Coe-Soft ${ }^{\mathrm{TM}}$ GC America Inc., Alsip, IL, USA).

About four weeks later [25], after tissue healing, with a dedicated tool (Cuff Height Measuring Tool, Rhein 83, Bologna, Italy), measurements of the transmucosal paths were performed and the most suitable retention systems means were chosen (OT Equator, Rhein 83, Bologna, Italy; Figure 10) and 
were screwed to the implant fixtures with a preset force, with the corresponding retentive copings. The provisional prosthesis is readapted to make it suitable to receive the stainless-steel retentive cap housing nylon retentive inserts, improving the stability and hold. The general rule to apply for the choice of this type of attachments is the retentive part, which must extend beyond the transmucosal path by at least one millimeter [26].

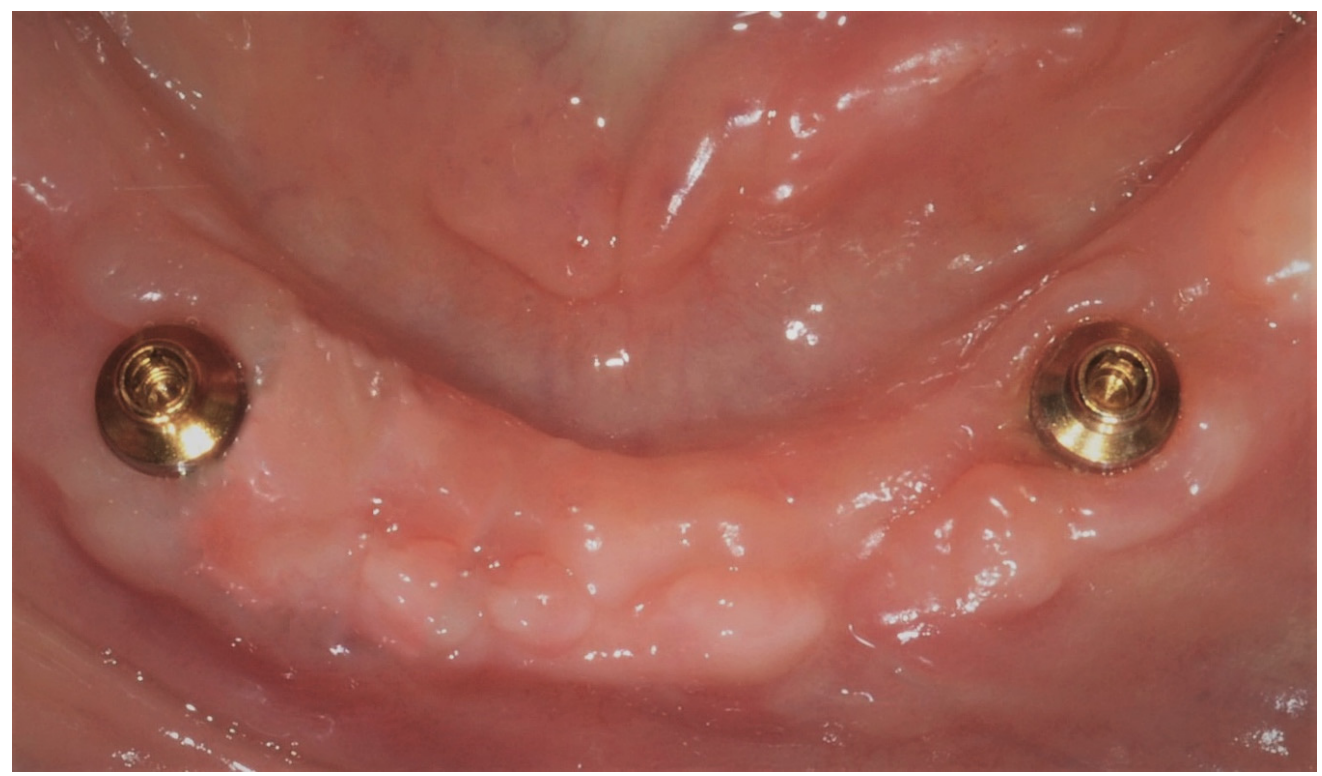

Figure 10. Equator attachments used to improve the stability and retention of prosthesis.

Thereafter the dental technician, using a 3D software (Exocad ${ }^{\circledR}$, Exocad $\left.\mathrm{GmbH}\right)$, plans the counter-bar [27], inserting retentive pins into the project for the mechanical hold of the teeth and preparing the area of the OT Equator attachment components (Rhein 83, Bologna, Italy).

The project is sent to the milling center (New Ancorvis, Bologna, Italia) indicating the type of metal to be used and the type of construction (laser melting technology). After being checked in the dental laboratory and sent to dentist for clinical testing, the precision and passivity of the piece is checked. The commercial teeth are then mounted, taking advantage of the prototype as a positioning guide. The perfectly polished prostheses are sent to the dental office (Figures 11-13), making sure there are no compression areas on the soft tissues. The patient is provided guidelines for prosthesis hygiene maintenance procedures.

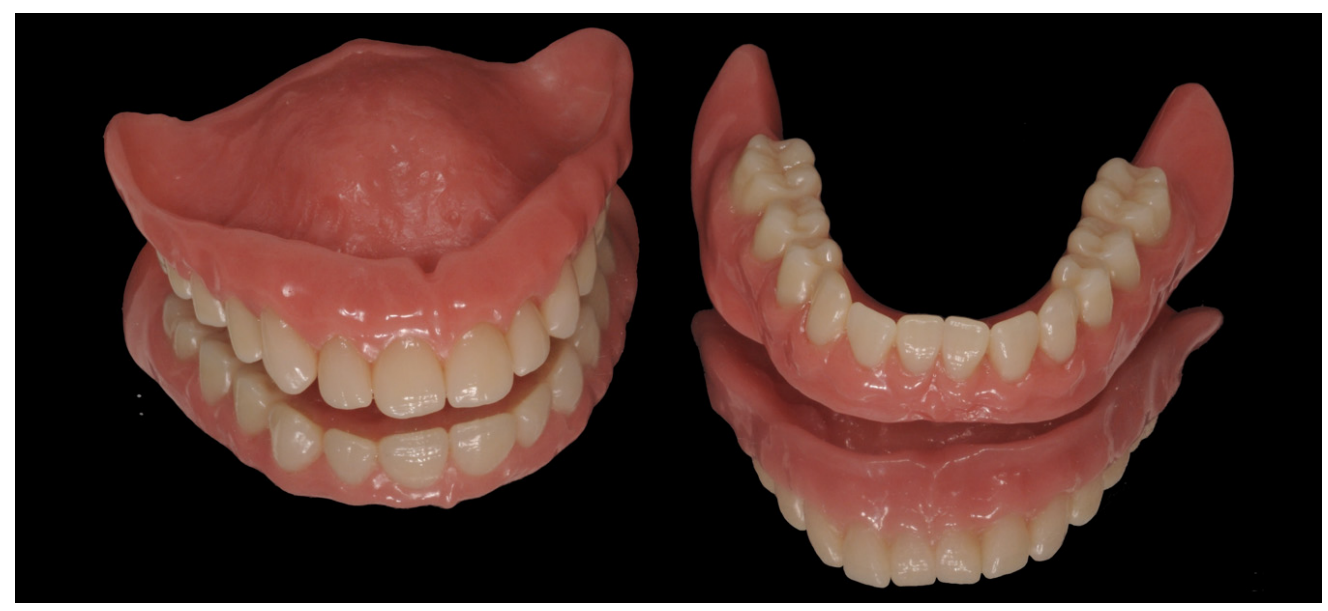

Figure 11. Details of the finished prosthesis. 


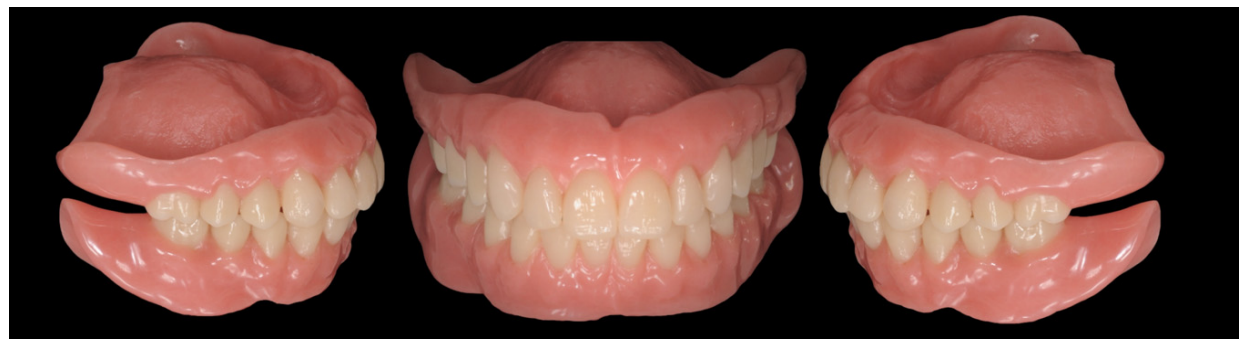

Figure 12. Completed dentures ready to be sent to the dental office.

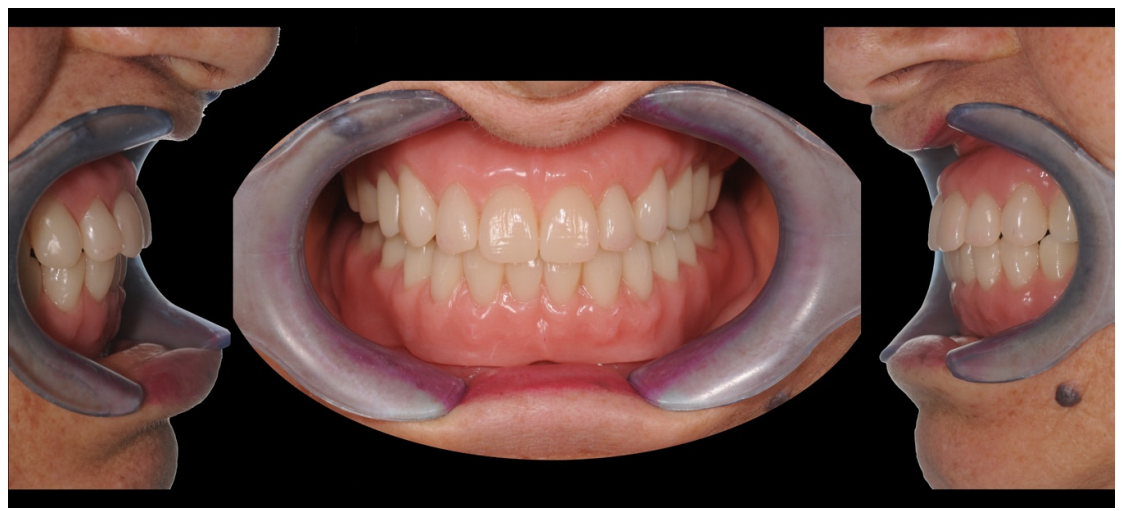

Figure 13. Postoperative intraoral view showing the good esthetic integration.

Once the prosthetic therapy was completed, the patient's face improved greatly from an esthetic viewpoint (Figure 14). The soft tissue of the face looked firm and toned. A reduction could be seen in the nasolabial folds and perilabial wrinkles (Figure 15), both frontally and laterally. The vertical dimension, which was slightly increased, appeared adequate and well-tolerated esthetically. During phonation and smiling dynamics the patient displayed natural looking teeth that were perfectly integrated with his face (Figure 16).

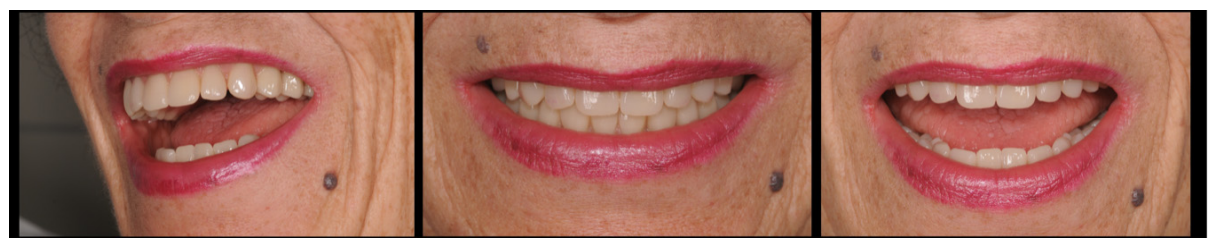

Figure 14. Patient's final smile with proper teeth position.

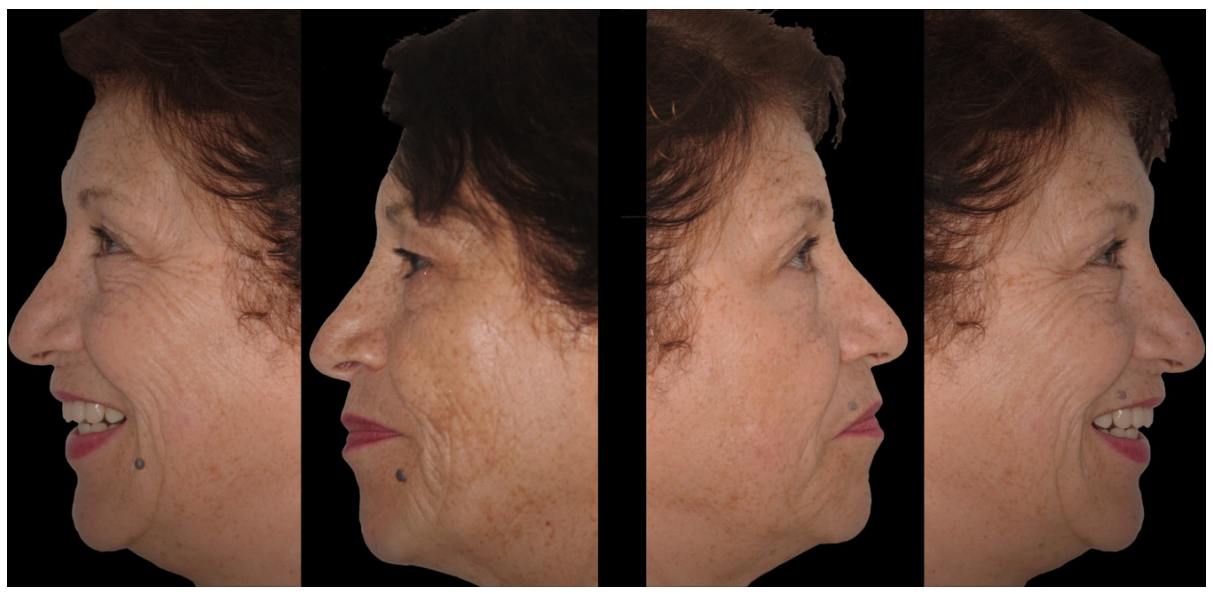

Figure 15. Patient's face in lateral view: the lip support appears correct. 


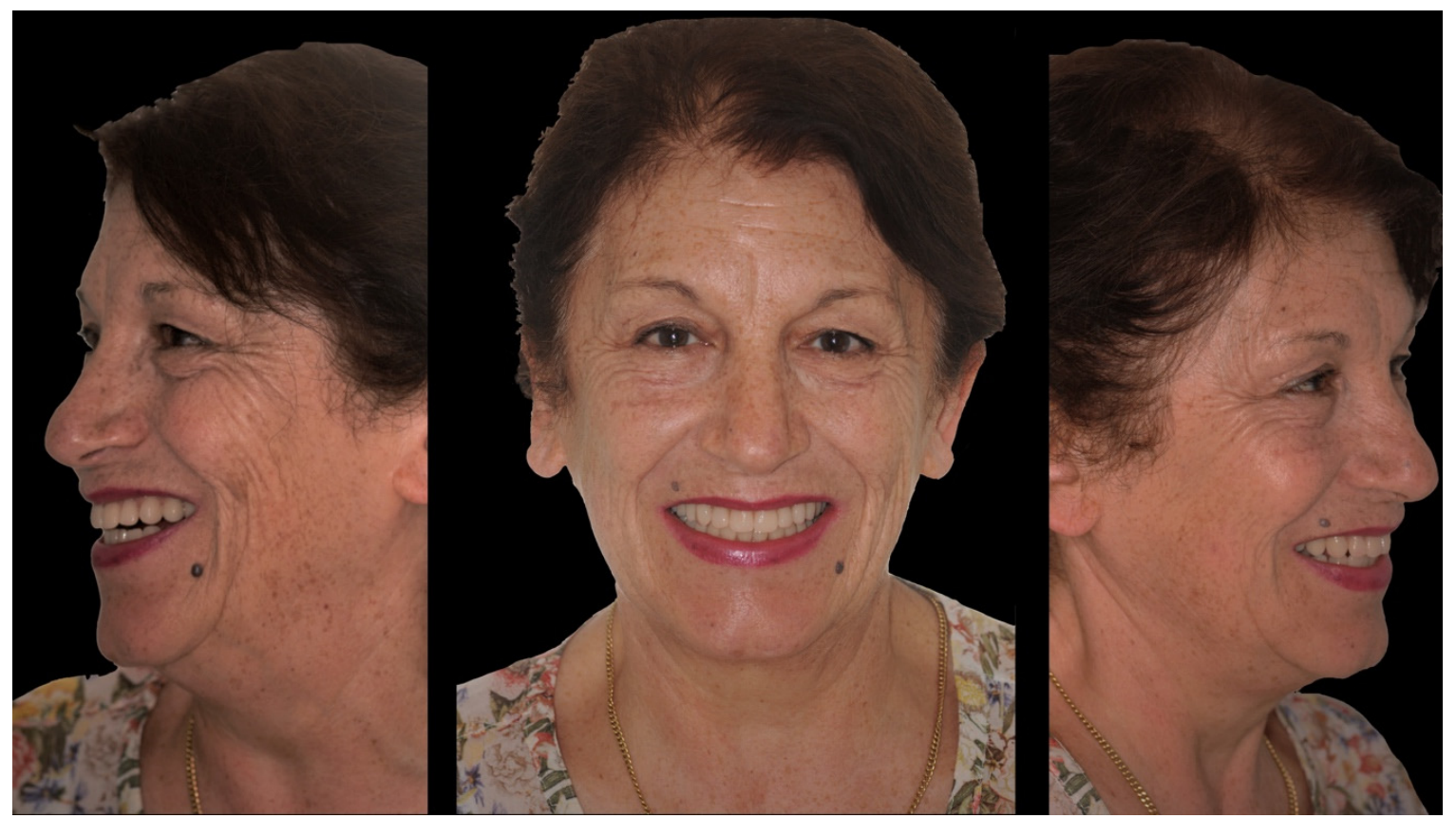

Figure 16. Patient's face at the end of the therapy: notice a reduction in the nasolabial folds and perilabial wrinkles.

\section{Discussion}

During the prosthetic therapy, for both fixed and removable prostheses, communication with the patient is a vital part of the treatment. Effective digital previewing is the ideal way to explain esthetic changes to a patient and to receive their approval. Until now, many digital previewing methods have been used in dentistry solely for this purpose. The authors deem that digital previewing of the smile must be inserted into a more complex workflow [28].

In this article, the Digital Smile System approach was introduced into a complex digital workflow. DSS (Digital Smile System, Bologna, Italy) not only allowed the patient to see their future appearance, but it also enabled production of a prototype for the functional check of the digital project carried out. The fact that the patient can see the possible future esthetic results through digital rendering, including the possibility of changes if desired, reduces overall clinical practice time. Additionally, the construction of a prototype, based on the virtual assembly, minimizes the number of errors in the manufacture of the final product and becomes a fundamental instrument for prosthetic-driven surgery. The decision-making process of using an implant overdenture prosthesis or a Toronto or hybrid prosthetic devices depends on different factors. The selection and extent of artificial tissues are related to facial support, emergence profile of the artificial tooth, the tooth angulation and the use of full flange extension is mentioned for esthetic advantages. However, the application of gingival prostheses may be limited to certain clinical situations where oral hygiene is manageable, function proper and esthetics acceptable. With a removable design, a larger volume of tissue can be replaced, and proper cleaning is still feasible. An instrument that could suggest a correct therapeutic choice is the latero-lateral radiography of the patient, which provides some important parameters: acrylic flange height, mucosal coverage, crown-Implant distance, and buccal prosthesis profile [16]. According to Avrampou et al., when the mucosal coverage is less than $5 \mathrm{~mm}$ and the prosthetic profile is up to 30 degrees, a fixed prosthesis whit hybrid or crown design can be selected. On the other hand, when the mucosal coverage is more than $5 \mathrm{~mm}$ and the prosthetic profile is less than 30 degrees, a removable prosthesis with a buccal flange is advised.

The use of overdenture involves different advantages. Compared to complete removable dentures, implant supported dentures have better stability and retention, improving function, esthetic, and satisfaction for the patient $[29,30]$. Furthermore, some data indicate that after receiving implants, 
patients with overdenture eat a diet with more fiber and hard foods than with conventional dentures, even if this does not improve nutritional intakes of essential micronutrients and macronutrients [31]. Furthermore, phonetic problems have been reported more often with fixed prostheses than with overdentures, probably because impaired phonetics appears to depend also on the palatal design of the prosthesis [32,33].

Use of the prototype as a radiological stent during the examination of the $\mathrm{CBCT}$, and its transformation into a surgery-driven guide make it possible to position implants according to the digital study done with the DSS and approved by the patient. Some phases of the described workflow require a learning curve by the clinical operator and technician. For example, the photos taken by the clinician for the DSS, must be taken in the exact manner as previously described to facilitate superimposing of the photo of the patient's face, with the scan of the model and the old denture. Another important stage is ensuring the teeth from the database of the 3D software are matched with the outlines obtained by digital previewing with the DSS. In this case, if the match is not precise, the prototype will not correspond perfectly with that approved by the patient [34].

\section{Conclusions}

The use of digital technologies is now vastly widespread in the field of dentistry and, in particular, in prosthetic therapy. In removable, traditional, and implant-supported prosthetic therapy, digital technology can play an essential role. The clinical case described was almost entirely done with an innovative digital workflow, both from clinical and technical viewpoints. In particular, guided surgery came into the digital workflow through a simplified approach that was closely dependent on the patient's esthetics and functional aspects. The human component is still fundamental and not all stages can be carried out digitally. However, it is expected that technical developments will rapidly lead to more and more digitalized therapies with an increase in the end quality of the therapy and less conditioned by the skills of the individual operator.

Author Contributions: Conceptualization, L.O.; methodology, L.O. and M.O.; software, L.O. and M.O.; resources, L.O.; data curation, F.G. and A.M.; writing—original draft preparation, L.O. and A.M.; writing-review and editing, L.O. and A.M.; visualization, L.O.; supervision, F.G.; M.O. fabricated the prosthesis. All authors have read and agreed to the published version of the manuscript.

Funding: This research received no external funding.

Acknowledgments: The authors thank Gianni Ortensi, Marco Ortensi, and Cesare Chiarini, who fabricated the prosthesis and supported laboratory digital processes.

Conflicts of Interest: The authors declare no conflict of interest.

\section{References}

1. Gupta, A.; Felton, D.A.; Jemt, T.; Koka, S. Rehabilitation of edentulism and mortality: A systematic review. J. Prosthodont. 2018, 28, 526-535. [CrossRef] [PubMed]

2. Kutkut, A.; Bertoli, E.; Frazer, R.; Pinto-Sinai, G.; Hidalgo, R.F.; Studts, J. A systematic review of studies comparing conventional complete denture and implant retained overdenture. J. Prosthodont. Res. 2018, 62, 1-9. [CrossRef] [PubMed]

3. Boven, G.C.; Raghoebar, G.; Vissink, A.; Meijer, H.J.A. Improving masticatory performance, bite force, nutritional state and patient's satisfaction with implant overdentures: A systematic review of the literature. J. Oral Rehabil. 2014, 42, 220-233. [CrossRef]

4. Schimmel, M.; Müller, F.; Suter, V.; Buser, D. Implants for elderly patients. Periodontol. 2000 2016, 73, $228-240$. [CrossRef]

5. Ortensi, L.; Stefani, R.; Ortensi, G. Edentulous superior maxillary: Choosing the proper implant-supported prosthetic solution. Spectr. Dialogue 2015, 14, 3. 
6. Tallarico, M.; Ortensi, L.; Martinolli, L.; Casucci, A.; Ferrari, E.; Malaguti, G.; Montanari, M.; Scrascia, R.; Vaccaro, G.; Venezia, P.; et al. Multicenter Retrospective Analysis of Implant Overdentures Delivered with Different Design and Attachment Systems: Results Between One and 17 Years of Follow-Up. Dent. J. 2018, 6, 71. [CrossRef]

7. Tallarico, M.; Cervino, G.; Scrascia, R.; Uccioli, U.; Lumbau, A.; Meloni, S.M. Minimally Invasive Treatment of Edentulous Maxillae with Overdenture Fully Supported by a Cad/Cam Titanium Bar with a Low-Profile Attachment Screwed on Four or Six Implants: A Case Series. Prosthesis 2020, 2, 6. [CrossRef]

8. Slot, W.; Raghoebar, G.M.; Cune, M.S.; Vissink, A.; Meijer, H.J. Maxillary overdentures supported by four or six implants in the anterior region: 5-year results from a randomized controlled trial. J. Clin. Periodontol. 2016, 43, 1180-1187. [CrossRef] [PubMed]

9. Coachman, C.C.; Calamita, M. Virtual Esthetic Smile Design. J. Cosmet. Dent. 2014, $29,4$.

10. Caviggioli, I.; Molinelli, F.; Ortensi, L.L.; Riccardo, S. La prima visita in odontoiatria protesica: Aspetti innovativi. Il Dentista Moderno 2011, 6, 46-54.

11. Lo Giudice, A.; Ortensi, L.; Farronato, M.; Lucchese, A.; Lo Castro, E.E.; Isola, G. The step further smile virtual planning: Milled versus prototyped mock-ups for the evaluation of the designed smile characteristics. BMC Oral Health 2020, 20, 165. [CrossRef] [PubMed]

12. Goodacre, C.J.; Garbacea, A.; Naylor, W.P.; Daher, T.; Marchack, C.B.B.; Lowry, J. CAD/CAM fabricated complete dentures: Concepts and clinical methods of obtaining required morphological data. J. Prosthet. Dent. 2012, 107, 34-46. [CrossRef]

13. Infante, L.; Yilmaz, B.; McGlumphy, E.E.; Finger, I. Fabricating complete dentures with CAD/CAM technology. J. Prosthet. Dent. 2014, 111, 351-355. [CrossRef]

14. Kattadiyil, M.T.; Jekki, R.; Goodacre, C.J.J.; Baba, N.Z. Comparison of treatment outcomes in digital and conventional complete removable dental prosthesis fabrications in a predoctoral setting. J. Prosthet. Dent. 2015, 114, 818-825. [CrossRef] [PubMed]

15. Tallarico, M.; Scrascia, R.; Annucci, M.; Meloni, S.; Lumbau, A.; Koshovari, A.; Xhanari, E.; Martinolli, M. Errors in Implant Positioning Due to Lack of Planning: A Clinical Case Report of New Prosthetic Materials and Solutions. Materials 2020, 13, 1883. [CrossRef] [PubMed]

16. Avrampou, M.; Mericske-Stern, R.; Blatz, M.B.; Katsoulis, J. Virtual implant planning in the edentulous maxilla: Criteria for decision making of prosthesis design. Clin. Oral Implant. Res. 2013, 24, 152-159. [CrossRef]

17. Ortensi, L.; Martini, M.; Montanari, M.; Galassini, G. A Simplified Method to Identify Patient Face Type for a Prosthodontic Treatment Plan. J. Dent. Health Oral Disord. Ther. 2017, 8, 1-5. [CrossRef]

18. Nishi, S.E.; Basri, R.; Alam, M.K. Uses of electromyography in dentistry: An overview with meta-analysis. Eur. J. Dent. 2016, 10, 419. [CrossRef]

19. Stefani, R.; Caviggioli, I.; Molinelli, F.; Ortensi, L. L'impiego delle tecnologie digitali nella diagnosi protesica e nella realizzazione della protesi. Il Dentista Moderno 2012, 10, 46-75.

20. McLaren, E.A.; Terry, D. Photography in dentistry. J. Calif. Dent. Assoc. 2001, 29, 735-742.

21. Ortensi, L.; Stefani, R.; Lavorgna, L.; Caviggioli, I.; Vitali, T. A Digital Workflow for an Implant Retained Overdenture: A New Approach. Biomed. J. Sci. Tech. Res. 2018, 6. [CrossRef]

22. D'Arienzo, L.F.; D'Arienzo, A.; Borracchini, A. Comparison of the suitability of intra-oral scanning with conventional impression of edentulous maxilla in vivo. A preliminary study. J. Osseointegr. 2018, 10, 115-120.

23. Bonato, G.; Borracchini, A.; Borromeo, C.; Capezzuto, V.; Casucci, A.; Chimenz, S.; Colognesi, R.; Colombo, M.; Gassino, G.; Ferrone, U.; et al. Aspetti Clinico Tecnici Nella Protesi Combinata; Teamwork Media srl: Brescia, Italy, 2015.

24. Joda, T.; Brägger, U.; Gallucci, G. Systematic literature review of digital three-dimensional superimposition techniques to create virtual dental patients. Int. J. Oral Maxillofac. Implant. 2015, 30, 330-337. [CrossRef]

25. Burkhardt, M.A.; Waser, J.; Milleret, V.; Gerber, I.; Emmert, M.; Foolen, J.; Hoerstrup, S.P.; Schlottig, F.; Vogel, V. Synergistic interactions of blood-borne immune cells, fibroblasts and extracellular matrix drive repair in an in vitro peri-implant wound healing model. Sci. Rep. 2016, 6, 21071. [CrossRef] [PubMed]

26. Scrascia, R.; Fiorillo, L.; Gaita, V.; Secondo, L.; Nicita, F.; Cervino, G. Implant-Supported Prosthesis for Edentulous Patient Rehabilitation. From Temporary Prosthesis to Definitive with a New Protocol: A Single Case Report. Prosthesis 2020, 2, 2. [CrossRef] 
27. Lavorgna, L.; Vitali, T.; Caviggioli, I.; Ortensi, L. Fully Digital Workflow for an Implant Retained Overdenture by Digital Smile Project to Guided Surgery and Prosthetic Rehabilitation. Int. J. Sci. Res. 2018, 7, 12.

28. Ortensi, L.; Vitali, T.; Bonfiglioli, R.; Grande, F. New Tricks in the Preparation Design for Prosthetic Ceramic Laminate Veeners. Prosthesis 2019, 1, 5. [CrossRef]

29. Doundoulakis, J.H.; Eckert, S.E.; Lindquist, C.C.; Jeffcoat, M.K. The implant-supported overdenture as an alternative to the complete mandibular denture. J. Am. Dent. Assoc. 2003, 134, 1455-1458. [CrossRef] [PubMed]

30. Assunção, W.G.; Zardo, G.G.; Delben, J.A.; Barão, V.A. Comparing the efficacy of mandibular implant-retained overdentures and conventional dentures among elderly edentulous patients: Satisfaction and quality of life. Gerodontology 2007, 24, 235-238. [CrossRef]

31. Hamada, M.O.; Garrett, N.R.; Roumanas, E.D.; Kapur, K.K.; Freymiller, E.; Han, T.; Diener, R.M.; Chen, T.; Levin, S. A randomized clinical trial comparing the efficacy of mandibular implant-supported overdentures and conventional dentures in diabetic patients. Part IV: Comparisons of dietary intake. J. Prosthet. Dent. 2001, 85, 53-60. [CrossRef]

32. Jemt, T. Failures and complications in 391 consecutively inserted fixed prostheses supported by branemark implants in edentulous jaws: A study of treatment from the time of prosthesis placement to the first annual checkup. Int. J. Oral Maxillofac. Implant. 1991, 6, 270-276.

33. Lundqvist, S.; Lohmander, A.; Haraldson, T. Speech before and after treatment with bridges on osseointegrated implants in the edentulous upper jaw. Clin. Oral Implant. Res. 1992, 3, 57-62. [CrossRef] [PubMed]

34. Lavorgna, L.; Cervino, G.; Fiorillo, L.; Di Leo, G.; Troiano, G.; Ortensi, M.; Galantucci, L.; Cicciù, M. Reliability of a Virtual Prosthodontic Project Realized through a 2D and 3D Photographic Acquisition: An Experimental Study on the Accuracy of Different Digital Systems. Int. J. Environ. Res. Public Health 2019, 16, 5139. [CrossRef] [PubMed]

(C) 2020 by the authors. Licensee MDPI, Basel, Switzerland. This article is an open access article distributed under the terms and conditions of the Creative Commons Attribution (CC BY) license (http://creativecommons.org/licenses/by/4.0/). 